\title{
An evaluation of hospital breastfeeding policies in the Philadelphia metropolitan area 1994-2009: a comparison with the baby-friendly hospital initiative ten steps.
}

\author{
Andrea Crivelli-Kovach \\ Arcadia University \\ Esther K Chung \\ Jefferson Medical College, Alfred I. DuPont Hospital for Children, Columbia University
}

Follow this and additional works at: https://jdc.jefferson.edu/pedsfp

Part of the Bioethics and Medical Ethics Commons, and the Pediatrics Commons

Let us know how access to this document benefits you

\section{Recommended Citation}

Crivelli-Kovach, Andrea and Chung, Esther K, "An evaluation of hospital breastfeeding policies in the Philadelphia metropolitan area 1994-2009: a comparison with the baby-friendly hospital initiative ten steps." (2011). Department of Pediatrics Faculty Papers. Paper 45.

https://jdc.jefferson.edu/pedsfp/45

This Article is brought to you for free and open access by the Jefferson Digital Commons. The Jefferson Digital Commons is a service of Thomas Jefferson University's Center for Teaching and Learning (CTL). The Commons is a showcase for Jefferson books and journals, peer-reviewed scholarly publications, unique historical collections from the University archives, and teaching tools. The Jefferson Digital Commons allows researchers and interested readers anywhere in the world to learn about and keep up to date with Jefferson scholarship. This article has been accepted for inclusion in Department of Pediatrics Faculty Papers by an authorized administrator of the Jefferson Digital Commons. For more information, please contact: JeffersonDigitalCommons@jefferson.edu. 


\title{
An Evaluation of Hospital Breastfeeding Policies in the Philadelphia Metropolitan Area 1994-2009: A Comparison with the Baby-Friendly Hospital Initiative Ten Steps
}

\author{
Andrea Crivelli-Kovach ${ }^{1}$ and Esther K. Chung ${ }^{2-4}$
}

\begin{abstract}
Objective: The purpose of this study was to describe current breastfeeding policies and practices among Philadelphia, PA metropolitan hospitals and changes in their policies and practices over time.

Methods: In-person group interviews were conducted to obtain a composite picture of actual breastfeeding policies and practices. One questionnaire per hospital was completed based on responses from group consensus. Twenty-five hospitals providing maternity care were contacted. Information was obtained from personnel representing different areas of maternity services. Hospitals were classified according to the degree to which they were implementing the Ten Steps to Successful Breastfeeding.

Results: Mean breastfeeding rates at suburban hospitals were significantly higher than urban hospitals $(72 \%$ vs. $49 \%, p=0.015)$. Most hospitals were classified as high or moderately high implementers on six of the Ten Steps, including staff training $(67 \%)$, printed information distributed to breastfeeding mothers $(94 \%)$, breastfeeding initiation $(61 \%)$, oral breastfeeding instruction given to mothers $(83 \%)$, infant feeding schedules $(89 \%)$, and hospital postpartum support (83\%). Most hospitals reported partial or low implementation on two maternity practices: infant formula supplementation $(61 \%)$ and rooming-in $(72 \%)$.

Conclusions: In the past 15 years, hospitals in the Philadelphia area have an increased awareness about breastfeeding and enhanced support of breastfeeding by healthcare professionals. In spite of an increase in overall breastfeeding rates, formula supplementation in hospitals and contact time between mothers and their newborns continue to be areas of concern.
\end{abstract}

\section{Introduction}

$\mathbf{T}$ he American Academy of Pediatrics recommends that mothers exclusively breastfeed their infants for the first year of the newborn's life and continue for as long as is mutually desirable by the mother and her child. ${ }^{1}$ Since 1990, there has been a consistent rise in breastfeeding rates at hospital discharge and 6 months postpartum. The increased awareness and growth of breastfeeding in general in the United States parallel the global recognition of the importance of breastfeeding as outlined in the Innocenti Declaration ${ }^{2}$ and the Baby-Friendly Hospital Initiative (BFHI), launched jointly by the World Health Organization and the United Nations Children's Fund (UNICEF) in 1991. ${ }^{3}$ The BFHI is the only global initiative that promotes breastfeeding within the hospital setting and is operationalized in the Ten Steps to Successful Breastfeeding. ${ }^{4}$

The Health People 2010 Guidelines set the following national breastfeeding goals: $75 \%$ of mothers breastfeed at hospital discharge, $50 \%$ breastfeed at 6 months, and $25 \%$ continue for up to a year postpartum. For exclusive breastfeeding, the goals include $40 \%$ of mothers exclusively breastfeed at 3 months postpartum and $17 \%$ at 6 months. ${ }^{5}$ Although the percentage of U.S. breastfeeding mothers has increased steadily since 1993 (55.9\% in 1993 vs. 66\% in 2003), the rates continue to fall short of the projected goals. ${ }^{6}$ Philadelphia, PA, the fifth largest U.S. city, ranks $10^{\text {th }}$ among the 10 largest cities for breastfeeding, with a breastfeeding initiation rate of $57 \%$

\footnotetext{
${ }^{1}$ Department of Medical Science and Community Health, Arcadia University, Glenside, Pennsylvania.

${ }^{2}$ Department of Pediatrics, Alfred I. duPont Hospital for Children, Wilmington, Delaware.

${ }^{3}$ Jefferson Medical College, Philadelphia, Pennsylvania.

${ }^{4}$ Institute on Medicine as a Profession, Columbia University, New York, New York.
} 
compared to the national average of $74 \%$ for babies born from 1999 to 2005 . 7,8

Research in 2001 showed that hospitals implementing the Ten Steps had a higher mean breastfeeding initiation rate than other U.S. hospitals (83.3\% vs. $69.5 \%) .{ }^{9}$ Researchers also found a positive dose-response relationship between the number of Steps implemented within the hospital and overall breastfeeding duration. ${ }^{10-12}$ Lactation difficulties during the hospital stay and within the first week following hospital discharge are associated with greater risk of early breastfeeding cessation and less success with breastfeeding future children. ${ }^{13}$ Breastfeeding outcomes are affected by inconsistencies seen in healthcare staff training, ${ }^{14}$ inadequate demonstration of proper breastfeeding techniques, ${ }^{15}$ prolonged separation of the mother-infant dyad and delayed breastfeeding initiation, ${ }^{16}$ and providing formula in the hospital discharge gift bags. ${ }^{17}$

A baseline evaluation of Philadelphia area hospital breastfeeding policies was conducted in $1994 .{ }^{18}$ A follow-up study in $1999^{19}$ showed significant changes in breastfeeding initiation, rooming-in, and hospital discharge support practices. The purpose of this study was (a) to describe the current status of breastfeeding policies and practices in metropolitan Philadelphia, (b) to assess current implementation of the Ten Steps, and (c) to assess changes in policies and practices and compare implementation levels of the Ten Steps with 1994 and 1999 data.

\section{Methods}

Twenty-five hospitals providing maternity services were identified in metropolitan Philadelphia, which includes Bucks, Chester, Delaware, Montgomery, and Philadelphia Counties. Since 1994, a total of 14 hospitals out of 39 providing maternity services have closed, merged services with other hospitals, or discontinued maternity care. Eighteen of the remaining 25 eligible hospitals (72\%) agreed to participate in the study, approved by the Institutional Review Boards of Thomas Jefferson University and the Crozer-Keystone Health System. The seven non-participating hospitals were classified as suburban community/teaching. Non-participation was due to pending closure $(n=2)$ or difficulty scheduling a group interview during the study period $(n=5)$. The suburban hospitals who participated represented all suburban counties and were comparable overall in hospital characteristics to those who participated in 1994 and 1999.

The principal investigators identified a nurse manager and/or lactation consultant at each hospital as the primary contact. A formal letter describing the study and requesting participation was sent electronically and by standard mail. This was followed up with a phone call to answer questions and set up a group interview. The primary contact invited key personnel, including nurse managers/directors, physicians, staff nurses, lactation consultants, and childbirth educators, to an in-person group interview to obtain a composite picture of breastfeeding policies and practices at each hospital. Group interviews were conducted to control for differing perspectives and to reach consensus on each question regarding the degree of implementation for maternity practices specified in the Ten Steps. One questionnaire per hospital was completed.

The questionnaire was updated from the original questionnaire developed in 1994 to reflect changes in hospital practices over the past 15 years. For example, skin-to-skin content as part of the hospital policy was added in the updated version. Core questions related to each of the Ten Steps and used to construct scores remained consistent with the original questionnaire to enable comparison of changes across time from 1994 to 2009. Questions were designed to measure the dimensions of the BFHI to determine the degree to which hospitals were implementing the Ten Steps.

The questionnaire was divided into 11 sections: one for hospital characteristics and the remainder for each of the Ten Steps. All questions within each section were coded as separate variables. Ten index variables representing the Ten Steps were created to classify hospitals' level of implementation on the Ten Steps individually and overall. For questions assessing frequency of practices, categories ranged from all or most of the time (76-100\%), often (51-75\%), sometimes (26-50\%), and seldom, if ever ( $0-25 \%)$ and were assigned a point value ranging from 4 to 1 . Points for each response within a given step were summed and divided by the number of questions used to measure implementation of that step. This produced a numerical and a categorical rating for implementation of each step and for the Ten Steps overall: high (3.26-4.00), moderate (2.51-3.25), partial (1.76-2.50), or low (1.00-1.75) implementation. Development of the original questionnaire, calculation of scaled scores, and the system used to classify hospitals by level of implementation of the Ten Steps were described previously. ${ }^{20}$

Breastfeeding rates were obtained from birth certificate data reported to the Pennsylvania Department of Health. The birth certificate data contain any breastfeeding (exclusive and partial) based on the newborn hospitalization and are, therefore, breastfeeding initiation rates. Frequencies were obtained for hospital characteristics, maternity practices, and implementation levels for each of the Ten Steps. Student's $t$ test was used to compare breastfeeding rates by hospital characteristics in 2009. A K-Related Samples test was used to compare implementation mean ranks across time measurement periods. All statistical comparisons were paired comparisons for the hospitals who participated in all three studies. SPSS version 17 (SPSS, Chicago, IL) (alpha $=0.05$ level of significance, two-tailed) was used for these analyses.

\section{Results}

Of the 18 participating hospitals, two-thirds (67\%) were classified as community hospitals with trainees (Table 1). Seven (39\%) are located in Philadelphia and classified as urban hospitals. A majority of hospitals (61\%) reported having a full-time lactation consultant on staff compared with only $16 \%$ in 1994 and $20 \%$ in 1999.

More than half of the hospitals in 2009 (61\%) reported breastfeeding rates between $61 \%$ and $100 \%$ compared with $32 \%$ in 1994 and 34\% in 1999 (Table 2). The mean breastfeeding rate $( \pm S D)$ for all participating hospitals was $62.9 \pm 21.5 \%$, representing an increase over the mean rates in $1994(48.3 \pm 19.9 \%, \quad p=0.006)$ and $1999(52.6 \pm 21.7 \%$, $p=0.037)$. Significant differences were also seen between mean breastfeeding rates reported by urban hospitals and suburban hospitals $(49.4 \pm 25.5 \%$ vs. $71.5 \pm 13.8 \%, p=0.029)$ and by primary payer mix $(76.0 \pm 12.8 \%$ private vs. $46.5 \pm 19.1$ public, $p=0.001$ ) (Table 2). 
Table 1. Hospital Characteristics

\begin{tabular}{|c|c|c|c|}
\hline \multirow[b]{2}{*}{ Characteristic } & \multicolumn{3}{|c|}{ n $(\%)$} \\
\hline & $1994(\mathrm{n}=38)$ & $1999(\mathrm{n}=35)$ & $2009(\mathrm{n}=18)^{\mathrm{a}}$ \\
\hline \multicolumn{4}{|l|}{ Hospital type } \\
\hline Community & $22(57.9)$ & $20(57.1)$ & $2(11.1)$ \\
\hline Community with trainees & $10(26.3)$ & $12(34.3)$ & $12(66.7)$ \\
\hline Medical school & $6(15.8)$ & $3(8.6)$ & $4(22.2)$ \\
\hline \multicolumn{4}{|l|}{ NICU classification } \\
\hline No NICU & $3(7.9)$ & $8(22.9)$ & $1(5.6)$ \\
\hline Level I/II NICU & $27(71.1)$ & $19(54.3)$ & $7(38.9)$ \\
\hline Level III NICU & $8(21.1)$ & $8(22.9)$ & $10(55.6)$ \\
\hline \multicolumn{4}{|l|}{ Deliveries/year } \\
\hline$\leq 1,000$ & $14(36.8)$ & $12(34.3)$ & $2(11.0)$ \\
\hline $1,001-2,500$ & $20(53.0)$ & $19(54.3)$ & $10(55.6)$ \\
\hline$>2,500$ & $4(10.5)$ & $5(11.4)$ & $6(33.4)$ \\
\hline \multicolumn{4}{|l|}{ Primary payer mix } \\
\hline Private/HMO & $28(73.7)$ & $26(74.3)$ & $9(50.0)$ \\
\hline Medicaid managed care & $10(26.3)$ & $9(25.7)$ & $7(38.9)$ \\
\hline \multicolumn{4}{|l|}{ Presence of an IBCLC } \\
\hline Yes (full-time) & $6(15.8)$ & $7(20.0)$ & $11(61.2)$ \\
\hline Yes (active part-time) & $8(21.1)$ & $10(28.6)$ & $5(27.7)$ \\
\hline No (limited part-time/no) & $24(63.2)$ & $18(51.5)$ & $2(11.1)$ \\
\hline \multicolumn{4}{|l|}{ Midwives deliver at hospital } \\
\hline Yes & $12(31.6)$ & $18(51.4)$ & $6(33.3)$ \\
\hline \multicolumn{4}{|l|}{ Hospital stay } \\
\hline \multicolumn{4}{|l|}{ Normal deliveries } \\
\hline Up to 25 hours & $30(78.9)$ & $2(5.7)$ & $1(5.6)$ \\
\hline 26-48 hours & $8(21.1)$ & $33(94.3)$ & $17(94.4)$ \\
\hline \multicolumn{4}{|l|}{ Cesarean deliveries } \\
\hline Up to 48 hours & $2(5.3)$ & 0 & $1(5.6)$ \\
\hline $49-72$ hours & $31(81.6)$ & $23(65.7)$ & $4(22.2)$ \\
\hline Over 72 hours & $5(13.2)$ & $12(34.3)$ & $13(72.2)$ \\
\hline \multicolumn{4}{|l|}{ Record breastfeeding data } \\
\hline Yes & $18(47.4)$ & $28(82.4)$ & $16(88.9)$ \\
\hline \multicolumn{4}{|l|}{ Record exclusive breastfeeding } \\
\hline Yes & NA & NA & $1(5.6)$ \\
\hline \multicolumn{4}{|l|}{ Data tabulated } \\
\hline Yes & $12(31.6)$ & $13(37.1)$ & $16(88.9)$ \\
\hline
\end{tabular}

${ }^{a}$ Where $n<18$ for 2009, selected hospitals did not report the information asked.

HMO, health maintenance organization; IBCLC, International Board Certified Lactation Consultant; NA, not available; NICU, neonatal intensive care unit.

\section{Ten Steps}

Step 1 (Formal policy): Have a written breastfeeding policy that is routinely communicated to all healthcare staff. The existence of a formal written policy was assessed to evaluate each hospital's commitment to promoting breastfeeding within the hospital setting. Integral to the existence of the policy is the extent to which the policy delineates specific practices included in the Ten Steps. Content of policies (the number of Steps included) were examined to determine the comprehensiveness of the policy and how the policy is communicated to staff and evaluated for effectiveness (Table 3 ).

The percent of hospitals with a formal policy increased from $74 \%$ in 1994 to $94 \%$ in 2009. Overall, there was a shift from $55 \%$ of the hospitals in 1994 having no policy or policies that included one or two BFHI Steps to $56 \%$ of the hospitals in 2009 including six to nine BFHI Steps.

Maternity practices related to the Ten Steps reflected in most policies included initiation of breastfeeding within 1 hour $(61 \%)$, breastfeeding support to maintain lactation
(89\%), restricting infant formula supplementation (67\%), encouraging breastfeeding on demand (89\%), and referring mothers to community resources following hospital discharge (61\%). Eight hospitals (44\%) reported including skin-to-skin contact as a component of their policy, which was not explored in 1994 or 1999 (Table 3).

All hospitals made the policy accessible to staff, while less than half posted it in the maternal and child unit $(28 \%)$ or on the intranet (44\%). Additionally, $44 \%$ of the hospitals reported a mechanism in place to evaluate the policy.

Step 2 (Healthcare staff training): Train all healthcare staff in skills necessary to implement this policy. In 2009, all hospitals, compared with 53\% in 1994 and 46\% in 1999, reported that most of the staff were informed of the breastfeeding policy, which occurs at orientation and during in-service trainings. Most hospitals (83\%) conducted formal in-service programs for nurses only with $28 \%$ conducting the trainings on a monthly, quarterly, or semiannual basis and 
Table 2. Breastfeeding Rates by Selected Hospital Characteristics

\begin{tabular}{|c|c|c|c|c|c|c|}
\hline & \multicolumn{2}{|c|}{1994} & \multicolumn{2}{|r|}{1999} & \multicolumn{2}{|r|}{2009} \\
\hline & $\mathrm{n}$ & Mean (SD) & $\mathrm{n}$ & Mean (SD) & $\mathrm{n}$ & Mean (SD) \\
\hline Overall breastfeeding rate ${ }^{a}$ & 38 & $48.3(19.9)$ & 35 & $52.6(21.7)$ & 18 & $62.9(21.5)$ \\
\hline \multicolumn{7}{|l|}{ Breastfeeding rates by location ${ }^{b}$} \\
\hline Urban hospitals & 18 & $35.5(18.8)$ & 14 & $37.9(23.6)$ & 7 & $49.4(25.5)$ \\
\hline Suburban hospitals & 20 & $59.8(12.7)$ & 21 & $62.4(13.6)$ & 11 & $71.5(13.8)$ \\
\hline \multicolumn{7}{|l|}{ Breastfeeding rates by payer mix ${ }^{c}$} \\
\hline Private/HMO & 27 & $57.9(13.3)$ & 26 & $59.9(17.8)$ & 10 & $76.0(12.8)$ \\
\hline \multirow[t]{2}{*}{ Medicaid/managed care } & 11 & $24.6(12.0)$ & 9 & $31.6(18.6)$ & 8 & $46.5(19.1)$ \\
\hline & \multicolumn{2}{|c|}{ n $(\%)$} & \multicolumn{2}{|r|}{$\mathrm{n}(\%)$} & \multicolumn{2}{|r|}{$\mathrm{n}(\%)$} \\
\hline \multicolumn{7}{|l|}{ Breastfeeding initiation level } \\
\hline 0-20\% & \multicolumn{2}{|c|}{$5(13.2)$} & \multicolumn{2}{|r|}{$3(8.6)$} & \multicolumn{2}{|r|}{$1(5.6)$} \\
\hline $21-40 \%$ & \multicolumn{2}{|c|}{$10(26.3)$} & \multicolumn{2}{|r|}{$5(14.3)$} & \multicolumn{2}{|r|}{$2(11.1)$} \\
\hline $41-60 \%$ & \multicolumn{2}{|c|}{$11(28.9)$} & \multicolumn{2}{|r|}{$15(42.8)$} & \multicolumn{2}{|r|}{$4(22.2)$} \\
\hline $61-80 \%$ & \multicolumn{2}{|c|}{$12(31.6)$} & \multicolumn{2}{|r|}{$9(25.7)$} & \multicolumn{2}{|r|}{$8(44.5)$} \\
\hline $81-100 \%$ & \multicolumn{2}{|c|}{0} & \multicolumn{2}{|r|}{$3(8.6)$} & \multicolumn{2}{|r|}{3 (16.7) } \\
\hline
\end{tabular}

${ }^{a}$ Overall breastfeeding rate is the mean rate for all participating hospitals for each study period. Significant differences seen between 1994 and 2009 at $p=0.006$ and between 1999 and 2009 at $p=0.037$ (analysis of variance).

bSignificant differences seen between urban and suburban hospitals in 2009 at $p=0.029$ (independent $t$ test).

'Significant differences seen between hospitals classified as serving mostly private/HMO patients or mostly Medicaid/managed care patients in 2009 at $p=0.001$ (paired $t$ test).

$72 \%$ conducting them annually. Less than 3 hours of breastfeeding training per year was offered by $61 \%$ of the hospitals, which has remained consistent over the past 15 years $(68 \%$ in 1994 and $63 \%$ in 1999), while 33\% offered between 3 and 8 hours of training per year.

Step 3 (Breastfeeding benefits and management): Inform all pregnant women about the benefits and management of breastfeeding. All hospitals reported offering prenatal classes, with $44 \%$ devoting more than 30 minutes to breastfeeding instruction and $83 \%$ offering a separate breastfeeding class for mothers. These results mirror what was reported in earlier surveys. Most hospitals (83\%) provided printed information on breastfeeding to all or most of the mothers, while a higher percentage of hospitals distributed in-house or childbirth organization information to mothers in 2009 compared to 1999 (78\% vs. 63\%). Fewer hospitals distributed formula company information on infant feeding to breastfeeding mothers in 2009 compared to 1994 (22\% vs. 55\%).

Step 4 (Breastfeeding initiation): Help mothers initiate breastfeeding within half an hour of birth. Differences in breastfeeding initiation between vaginal and cesarean birth mothers persist, with this, in part, being attributable to differences in immediate postpartum care. The majority of hospitals $(61 \%)$ reported over 30 minutes of contact between a mother and her baby post-vaginal birth, but few report contact that exceeded an hour. Most hospitals (83\%) reported the baby being put to the breast within the first hour following delivery. More than half (56\%) reported separation of mothers from their babies with initial nursery stays of up to 2 hours, and another $39 \%$ reported nursery stays of up to 2-4 hours after initial contact time. Only one hospital (6\%) reported never separating mothers and babies compared with $17 \%$ in 1999.
For mothers with cesarean births, most hospitals (72\%) reported encouraging the mothers to hold their babies after recovery, and $44 \%$ reported the initial contact time as being over 30 minutes (18\% in 1994 and 34\% in 1999). Some hospitals $(44 \%)$ reported the first breastfeeding 3-8 hours after recovery compared with $43 \%$ in 1999 and $60 \%$ in 1994 . Fewer hospitals $(17 \%)$ reported the first feeding within the first hour after recovery compared with $37 \%$ in 1999 . Regarding nursery stays, 39\% of the hospitals reported less than 2-hour stays, $44 \%$ reported $2-4$-hour nursery stays, and $11 \%$ kept babies in the nursery for 5 or more hours, a decrease from 60\% in 1994 and $46 \%$ in 1999. One hospital reported never separating the mother-infant dyad following cesarean section.

Step 5 (Breastfeeding education and support): Show mothers how to breastfeed, and maintain lactation even if they should be separated from their infants. Most hospitals $(61 \%)$ reported having a full-time International Board Certified Lactation Consultant (IBCLC) on staff compared with only $16 \%$ in 1994 and $20 \%$ in 1999 . Few hospitals (11\%) reported no or limited IBCLC staffing.

There were no significant changes in the amount of instruction that mothers received during their hospital stay from earlier surveys or in the support that breastfeeding mothers with babies in the neonatal intensive care units receive. Most hospitals reported giving instruction with the first feeding $(94 \%)$ and that mothers of babies in special care are supported in their efforts to breastfeed (83\%).

Step 6 (Infant formula supplementation): Give newborn infants no food or drink other than breastmilk, unless medically indicated. A majority of hospitals (67\% for vaginal births, 50\% for cesarean births) reported giving newborns breastmilk as a first feeding all or most of the time compared with $47 \%$ in 1994 and $89 \%$ in 1999. Most hospitals (89\%) 
Table 3. Hospitals Reporting Formal Breastfeeding Policies (Step 1) by Year and Content

\begin{tabular}{|c|c|c|c|}
\hline & \multicolumn{3}{|c|}{ n ( \% yes $)$} \\
\hline & $1994(\mathrm{n}=38)$ & $1999(\mathrm{n}=35)$ & $2009(\mathrm{n}=18)$ \\
\hline \multicolumn{4}{|l|}{ Formal policy } \\
\hline Have a formal policy & $28(73.7)$ & $30(85.8)$ & $17(94.4)$ \\
\hline \multicolumn{4}{|l|}{ Policy calls for: } \\
\hline a. formal in-service for staff & $5(13.2)$ & $5(14.3)$ & $5(27.8)$ \\
\hline b. prenatal classes & $5(13.2)$ & $8(22.9)$ & $6(33.3)$ \\
\hline c. initiate breastfeeding within 1 hour & $22(57.9)$ & $23(65.7)$ & $11(61.1)$ \\
\hline d. breastfeeding support to maintain lactation & $20(52.6)$ & $20(57.1)$ & $16(88.9)$ \\
\hline e. restrict infant supplementation & $13(34.2)$ & $24(68.6)$ & $12(66.7)$ \\
\hline f. encourage 24 -hour rooming-in & $14(36.8)$ & $15(42.9)$ & $9(50.0)$ \\
\hline g. encourage breastfeeding on demand & $24(63.2)$ & $27(77.1)$ & $16(88.9)$ \\
\hline h. restrict the use of pacifiers & $5(13.2)$ & $9(25.7)$ & $7(38.9)$ \\
\hline j. refer mothers to community resources & $18(47.4)$ & $19(54.3)$ & $11(61.1)$ \\
\hline k. refer problems to appropriate resources & $16(42.1)$ & $16(45.7)$ & $11(61.1)$ \\
\hline 1. include skin-to-skin contact & NA & NA & $8(44.4)$ \\
\hline \multicolumn{4}{|l|}{ Availability of policy } \\
\hline Policy available for referral by staff & $27(71.1)$ & $29(82.9)$ & $18(100)$ \\
\hline Policy posted in maternal/child unit & $3(7.9)$ & $2(5.7)$ & $5(27.8)$ \\
\hline Available on hospital website (intranet) & NA & NA & $8(44.4)$ \\
\hline \multicolumn{4}{|l|}{ Policy evaluation } \\
\hline Mechanism to evaluate the policy & $11(28.9)$ & $9(25.7)$ & $8(44.4)$ \\
\hline
\end{tabular}

reported giving formula supplements compared with $37 \%$ in 1994 and 1999. Many hospitals (68\%) reported that more than half the time formula supplements were given at the mother's request.

More hospitals (44\%) in 2009 reported displaying promotional materials for infant formulas compared with $29 \%$ in 1994 and 34\% in 1999. Most hospitals (94\%) distributed separate discharge bags to breastfeeding mothers, but only $6 \%$ distributed bags without formula or coupons, compared with $16 \%$ in 1994.

Step 7 (Rooming-in) Practice rooming-in-that is, allow mothers and infants to remain together-24 hours a day. Most hospitals (94\%) reported having a written policy that allows mothers to room-in 24 hours with their newborns compared with $73 \%$ in 1994 and $94 \%$ in 1999. However, approximately half of the hospitals (56\%) reported few mothers choosing 24-hour rooming-in. There was an increase in the percentage of hospitals $(56 \%)$ reporting most mothers spending over 16 hours/day with their babies (26\% in 1999 , $13 \%$ in 1994), and $44 \%$ reported most mothers spending from 9 to 16 hours (87\% in 1994 and 71\% in 1999). Most hospitals reported separating babies from their mothers for pediatric rounds $(94 \%)$, hearing tests $(100 \%)$, heel sticks $(100 \%)$, infant baths $(83 \%)$, mother baths $(89 \%)$, and phototherapy $(100 \%)$.

Step 8 (Feeding schedules): Encourage breastfeeding on demand. Most hospitals (83\%) encourage mothers to feed their newborns on demand and are taught to recognize hunger cues, similar to results shown in 1994 and 1999. An increase in the percentage of hospitals (39\%) that reported limiting the length of feedings (29\% in 1994 and 20\% in 1999) was seen with many hospitals expressing concern about patient satisfaction. Of importance is that only 33\% reported bringing the babies to their mothers at night to breastfeed compared with 76\% in 1994 and 89\% in 1999. Most hospitals $(83 \%)$ reported giving babies formula at night if they were not brought to their mothers.

Step 9 (Pacifier use): Give no additional teats or pacifiers to breastfeeding infants. Most hospitals (83\%) reported using pacifiers, noting that this is often at the mother's request, similar to $1994(77 \%)$ and $1999(84 \%)$.

Step 10 (Hospital discharge support): Foster the establishment of breastfeeding support groups and refer mothers to them on discharge from the hospital or clinic. Support for breastfeeding mothers following discharge from the hospital increased from earlier surveys with $89 \%$ reported giving various types of support versus 45\% in 1994 and 46\% in 1999 . The most frequently offered types of support included home visits covered by insurance (83\%) and referral to (a) support groups (78\%), (b) a lactation consultant (83\%), (c) the Special Supplemental Nutrition Program for Women, Infants and Children (100\%), and (e) an outpatient lactation clinic (56\%). Fewer hospitals (33\%) reported follow-up telephone calls or follow-up visits at the hospital (17\%). Half of the hospitals $(50 \%)$ reported having breastfeeding support groups on site, an increase from only 16\% in 1994 and 23\% in 1999.

\section{Hospital level of implementing the Ten Steps}

Implementation level of hospitals on each of the Ten Steps and overall is summarized in Table 4. Most hospitals (72\%) were classified as high or moderate implementers overall in 2009 (37\% in 1994 and 51\% in 1999), representing an increase in implementation levels for the surveyed hospitals since 1994. Most hospitals were classified as high or moderate implementers for six of the Ten Steps: Step 2 (staff training, 67\%), Step 3 (breastfeeding information, 94\%), Step 4 (breastfeeding 
Table 4. Hospital Implementation Level on the Ten Steps by Percentage of Hospitals Ranked By CATEgory AND YeAR

\begin{tabular}{|c|c|c|c|}
\hline Step & Title & $\begin{array}{c}\text { High/ } \\
\text { moderate } \\
(\%)\end{array}$ & $\begin{array}{c}\text { Partial/ } \\
\text { low } \\
(\%)\end{array}$ \\
\hline \multirow[t]{4}{*}{1} & Formal policy & & \\
\hline & 1994 & 34.2 & 65.8 \\
\hline & 1999 & 28.6 & 71.4 \\
\hline & 2009 & 50.0 & 50.0 \\
\hline \multirow[t]{4}{*}{2} & Staff training & & \\
\hline & 1994 & 26.3 & 73.7 \\
\hline & 1999 & 31.4 & 68.6 \\
\hline & 2009 & 66.7 & 33.3 \\
\hline \multirow[t]{4}{*}{3} & $\begin{array}{l}\text { Breastfeeding education } \\
\text { and benefits }\end{array}$ & & \\
\hline & 1994 & 100.0 & \\
\hline & 1999 & 97.1 & 2.9 \\
\hline & 2009 & 94.4 & 5.6 \\
\hline \multirow[t]{4}{*}{4} & Initiating breastfeeding & & \\
\hline & 1994 & 39.5 & 60.5 \\
\hline & 1999 & 71.4 & 28.6 \\
\hline & 2009 & 61.1 & 38.9 \\
\hline \multirow[t]{4}{*}{5} & $\begin{array}{l}\text { Breastfeeding support } \\
\text { to maintain lactation }\end{array}$ & & \\
\hline & 1994 & 65.8 & 34.2 \\
\hline & 1999 & 65.7 & 34.3 \\
\hline & 2009 & 83.3 & 16.7 \\
\hline \multirow[t]{4}{*}{6} & Infant supplementation & & \\
\hline & 1994 & 26.3 & 73.7 \\
\hline & 1999 & 14.3 & 85.7 \\
\hline & 2009 & 38.9 & 61.1 \\
\hline \multirow[t]{4}{*}{7} & Rooming-in & & \\
\hline & 1994 & 10.5 & 89.5 \\
\hline & 1999 & 34.3 & 65.7 \\
\hline & 2009 & 27.8 & 72.2 \\
\hline \multirow[t]{5}{*}{8} & Feeding schedules: & & \\
\hline & $\begin{array}{l}\text { Breastfeeding } \\
\text { on demand }\end{array}$ & & \\
\hline & 1994 & 89.4 & 10.6 \\
\hline & 1999 & 97.1 & 2.9 \\
\hline & 2009 & 88.9 & 11.1 \\
\hline \multirow[t]{4}{*}{9} & Pacifier use & & \\
\hline & 1994 & 31.6 & 68.4 \\
\hline & 1999 & 28.9 & 71.4 \\
\hline & 2009 & 11.2 & 88.9 \\
\hline \multirow[t]{5}{*}{10} & Hospital discharge & & \\
\hline & $\begin{array}{l}\text { education } \\
\text { and support }\end{array}$ & & \\
\hline & 1994 & 57.9 & 42.1 \\
\hline & 1999 & 57.2 & 42.8 \\
\hline & 2009 & 83.4 & 16.6 \\
\hline \multirow{3}{*}{$\begin{array}{l}\text { Ten Steps } \\
\text { overall rating }\end{array}$} & 1994 & 36.8 & 63.2 \\
\hline & 1999 & 51.4 & 48.6 \\
\hline & 2009 & 72.2 & 27.8 \\
\hline
\end{tabular}

There were 38 hospitals surveyed in 1994, 35 in 1999, and 18 in 2009.

initiation, 61\%), Step 5 (breastfeeding support and instruction, $83 \%$ ), Step 8 (feeding schedules, 89\%), and Step 10 (hospital discharge support, $83 \%$ ).

A K-Related Samples test for mean implementation ranks was conducted to evaluate whether hospital levels of implementing each of the Ten Steps in 2009 differed from those measured in 1994 and 1999. Mean implementation ranks differed significantly for Step 4 (breastfeeding initiation) $\left[\chi^{2}\right.$ $(2, n=17)=6.17, p=0.045]$, Step 7 (rooming-in) $\left[\chi^{2}(2\right.$, $n=17)=6.24, p=0.044]$, and Step 8 (breastfeeding on demand) $\left[\chi^{2}(2, n=17)=18.16, p<0.001\right]$.

\section{Discussion}

Changing hospital breastfeeding policies and practices creates an atmosphere that both protects and supports the mother-infant dyad. Researchers have examined the impact of the Ten Steps to Successful Breastfeeding on breastfeeding promotion in the hospital setting. ${ }^{18-27}$ Results of this study showed changes over the past 15 years in formal policy, staff training, breastfeeding initiation and formula supplementation, and breastfeeding support following hospital discharge.

\section{Formal breastfeeding policies}

Results showed an increase in hospitals with formal breastfeeding policies that included most of the maternity practices noted in the Ten Steps. Additionally, a number of hospitals promoted skin-to-skin contact, which is associated with higher rates of breastfeeding initiation and breastfeeding at 1-4 months postpartum when implemented shortly after delivery. ${ }^{28}$ Having a formal policy that includes most of the BFHI recommendations demonstrates the hospital's commitment to promoting breastfeeding and provides the platform for ensuring staff training and education and support of mothers. $^{10-12}$

\section{Staff training}

Knowledge of breastfeeding management and professional attitudes influence a mother's infant feeding decision and support her hospital experience. Professional knowledge is central to reducing the amount of misinformation and inconsistent advice given to breastfeeding mothers that can negatively impact a mother's experience. The BFHI recommends 18 hours of training for healthcare professionals and staff working with breastfeeding mothers. ${ }^{14,29-32}$ In 2009, more hospitals reported offering annual in-service programs for their staff but provide on average less than 3 hours of training. Nurses wanting more in-depth training need to do so outside the hospital setting. Lactation consultants receive indepth training annually as a requirement for their certification, and research shows that the presence of an IBCLC within the hospital increases breastfeeding rates. ${ }^{33}$

\section{Breastfeeding initiation and supplementation}

Separation of the mother-infant dyad during the hospital stay is a barrier to breastfeeding, and hospital practices that routinely separate mothers and babies, delay breastfeeding, and/or use supplementary formula feedings impact breastfeeding duration. ${ }^{34-38}$ Most vaginal birth babies initiate breastfeeding early, whereas cesarean birth babies often experience delays in initiating feedings. This practice increases the likelihood that babies will receive formula supplements while separated from their mothers in the nursery. ${ }^{12}$ Initial evaluation in the nursery for all babies is still the norm in Philadelphia, with more hospitals separating the motherinfant dyad for up to 2 hours than reported in 1999. Nearly $40 \%$ of the hospitals reported that babies are receiving for- 
mula supplementation over $50 \%$ of the time, and $68 \%$ reported that often supplements are given at the mother's request. This represents a higher level of supplementation than that reported earlier, which may be due to several factors, including changes related to hospital closures, patient demand for mixed feedings, and the need to supplement when infants exhibit jaundice or low blood sugar.

\section{Hospital discharge support}

Support of the new mother outside the hospital setting is critical for breastfeeding maintenance and duration ${ }^{39,40}$ but remains a challenge for health professionals, particularly if there is limited access to outpatient lactation support programs. Hospitals in this study showed increased levels of outside support with telephone calls, home visits, and referral to support groups and lactation clinics. Support following discharge from the hospital is essential until breastfeeding is established.

\section{Hospital implementation of Ten Steps}

Comparisons across measurement periods from 1994 to 2009 for the 18 participating hospitals showed significant differences in mean ranks for breastfeeding initiation, rooming-in, and breastfeeding on demand. In each case, improvements in implementing these steps made from 1994 to 1999 shifted in a negative direction from 1999 to 2009, indicating the need for improvement in initiating breastfeeding within an hour after delivery, keeping the mother-infant dyad together as recommended by the BFHI, and monitoring infant formula supplementation, including night feedings.

\section{Limitations and significance}

Since 1994, a significant number of maternity services in metropolitan Philadelphia closed (36\% decrease from 1994 to 2009). Although the hospitals participating in the study were similar overall in hospital characteristics to those that participated in earlier studies, the small number sampled makes comparisons of the cohorts across time periods difficult. All statistical comparisons are paired comparisons for the hospitals that participated in all three studies.

The significance of this study relates to the implementation of key maternity practices, such as breastfeeding initiation, infant supplementation, and rooming-in, reported by hospitals across the United States. ${ }^{10-12}$ Additionally, the concerted efforts of a strong breastfeeding advocacy and support network in metropolitan Philadelphia, committed to the BFHI, extends breastfeeding support beyond the hospital to a broader healthcare support network, including community organizations, primary care professionals, and hospitals. The challenge lies in determining how the needs of the motherinfant dyad can be served best by each member of this network to promote and support breastfeeding.

\section{Summary}

Results of this study showed an increase in the percentage of hospitals rated as moderate implementers of the Ten Steps overall. Despite this increase, several hospitals are still classified as partial or low implementers. Most hospitals have included more Steps in their formal policies, which indicates organizational support of breastfeeding and sets the stage for meaningful change in how policies are implemented in practice. Initiating breastfeeding shortly after delivery helps to establish breastfeeding, but practices such as formula supplementation, night feedings, and separation of the mother-infant dyad are associated with early breastfeeding termination and shorter breastfeeding duration. The challenge remains for hospitals to address implementation of maternity practices identified in their policies as providing a supportive environment for breastfeeding mothers.

\section{Acknowledgments}

We would like to thank the Breastfeeding Advisory Committee of Maternity Care Coalition for their assistance in identifying hospitals and hospital contacts and Molly Crispell for her assistance with data entry. This work, in part, was made possible through the support of the Physician Advocacy Fellowship at the Institute on Medicine as a Profession at Columbia University College of Physicians and Surgeons.

\section{Disclosure Statement}

No competing financial interests exist.

\section{References}

1. Gartner LM, Morton J, Lawrence RA, et al. Breastfeeding and use of human milk. Pediatrics 2005;115:496-506.

2. World Health Organization/UNICEF. Innocenti Declaration: On the Protection, Promotion, and Support of Breastfeeding. Breastfeeding in the 1990s: Global Initiative. World Health Organization/UNICEF, Florence, Italy, 1990.

3. World Health Organization/UNICEF. Protecting, Promoting and Supporting Breastfeeding: The Special Role of Maternity Services. A Joint WHO/UNICEF Statement. World Health Organization/UNICEF, Geneva, 1989.

4. World Health Organization/UNICEF. Ten Steps to Successful Breastfeeding. World Health Organization, Geneva, 1989.

5. U.S. Department of Health and Human Services. Healthy People 2010, Vol. II. Office of the Assistant Secretary of Health, U.S. Department of Health and Human Services, Washington, DC, 2000.

6. Ryan AS, Wenjun Z, Acosta A. Breastfeeding continues to increase into the new millennium. Pediatrics 2002;110:1103-1109.

7. Pennsylvania Department of Health. Breastfeeding Initiation in Pennsylvania Birthing Hospitals. 2008. www.dsf.health .state.pa.us/health/cwp/view.asp?a $=179 \& Q=251184 \& P M$ (accessed October 28, 2008).

8. Centers for Disease Control and Prevention. Breastfeeding Among US Children Born 1999-2005: CDC National Immunization Survey. 2008. www.cdc.gov/breastfeeding/ data/nis_data/index.htm (accessed October 4, 2008).

9. Merewood A, Mehta S, Chamberlain K, et al. Breastfeeding rates in US Baby-Friendly Hospitals: Results of a national survey. Pediatrics 2005;116:628-634.

10. Chien LY, Tai CJ, Chu KH, et al. The number of Baby Friendly hospital practices experienced by mothers is positively associated with breastfeeding: A questionnaire survey. Int J Nurs Stud 2007;44:1138-1146.

11. Murray EK, Rickets S, Dellaport J. Hospital practices that increase breastfeeding duration: Results from a populationbased study. Birth 2007;34:202-211.

12. DiGirolamo AM, Grummer-Strawn LM, Fein SB. Effects of maternity care practices on breastfeeding. Pediatrics 2008; 122(Suppl 2):S43-S49. 
13. Hall R, Mercer A, Teasley S, et al. A breastfeeding assessment score to evaluate the risk of cessation of breastfeeding by 7 to 10 days of age. J Pediatr 2002;141:659-664.

14. Schanler RJ, O'Connor KG, Lawrence RA. Pediatricians' practices and attitudes regarding breastfeeding promotion. Pediatrics 1999;103:e35.

15. Hong TM, Callister LC, Schwartz R. First-time mothers' views of breastfeeding support from nurses. Am J Matern Child Nurs 2003;28:10-15.

16. Svensson K, Matthiesen AS, Widstrom AM. Night roomingin: Who decides? An example of staff influence on mother's attitude. Birth 2005;32:99-108.

17. Rosenberg KD, Eastham CA, Kasenhagen LJ, et al. Marketing infant formula through hospitals: The impact of commercial hospital discharge packs on breastfeeding. Am J Public Health 2008;98:290-295.

18. Crivelli-Kovach A. Hospital breastfeeding policies in the Philadelphia area: A comparison with the WHO/UNICEF Ten Steps. Birth 1997;24:41-48.

19. Crivelli-Kovach A. A 5-year follow-up study of hospital breastfeeding policies in the Philadelphia area: A comparison with the Ten Steps. J Hum Lact 2002;18:144-154.

20. Crivelli Kovach A. An assessment tool for evaluating hospital policies and practices. J Hum Lact 1996;12:41-45.

21. Centers for Disease Control and Prevention (CDC). Breastfeeding-related maternity practices at hospitals and birth centers-United States, 2007. MMWR Morbid Mortal Wkly Rep 2008;57:621-625.

22. Karra M, Auerbach KG, Olson L, et al. Hospital infant feeding practices in metropolitan Chicago: An evaluation of 5 of the Ten Steps to Successful Breastfeeding. I Am Diet Assoc 1993;91:1437-1439.

23. Declercq E, Labbock MH, Sakala C, et al. Hospital practices and women's likelihood of fulfilling their intention to exclusively breastfeed. Am J Public Health. 2009;99:929-935.

24. Levitt CA, Kaczorowski J, Hanvey L, et al. Breast-feeding policies and practices in Canadian hospitals providing maternity care. CMAJ 1996;155:181-188.

25. Wright A, Rice S, Wells S. Changing hospital practices to increase duration of breastfeeding. Pediatrics 1996;97: 669-675.

26. Perez-Escamilla R, Pollitt E, Lonnerdal B, et al. Infant feeding policies in maternity wards and their effect on breastfeeding success: An analytical overview. Am J Public Health 1994;84:89-97.

27. Rivera-Lugo M, Parrilla-Rodriquez AM, Davila-Torres RR, et al. Full breastfeeding during the postpartum hospitalization and mothers' report regarding baby-friendly practices. Breastfeed Med 2007;2:19-26.

28. Walker M. Breastfeeding: Good starts, good outcomes. J Perinat Neonatal Nurs 2007;21:191-197.
29. Barnett E, Sienkiewicz M, Roholt S. Beliefs about breastfeeding: A statewide survey of health professionals. Birth 1995;22:15-20.

30. Spear HJ. Nurses' attitude, knowledge, and beliefs related to the promotion of breastfeeding among women who bear children during adolescence. J Pediatr Nurs 2004;19:176-183.

31. Taveras EM, Li R, Grummer-Strawn LM, et al. Opinions and practices of clinicians associated with continuation of exclusive breastfeeding. Pediatrics 2004;113:e283-e290.

32. Nelson AM. Maternal newborn nurses' experiences of inconsistent professional breastfeeding support. J Adv Nurs 2007;60:29-38.

33. Castrucci BC, Hoover KL, Lim S, et al. Availability of lactation counseling services influences breastfeeding among infants admitted to neonatal intensive care units. Am J Health Promot 2007;21:410-415.

34. Rowe-Murray HJ, Fisher JR. Baby friendly hospital practices: Cesarean section is a persistent barrier to early initiation of breastfeeding. Birth 2002;29:124-132.

35. Gill SL, Reifsnider E, Lucke JF. Effects of support on the initiation and duration of breastfeeding. West J Nurs Res 2007;29:708-723.

36. Dewey KG, Nommsen-Rivers LA, Heinig MJ, et al. Risk factors for suboptimal infant breastfeeding behavior, delayed onset of lactation, and excess neonatal weight loss. Pediatrics 2003;112:607-619.

37. Grummer-Strawn L, Scanlon KS, Fein SB. Infant feeding and feeding transitions during the first year of life. Pediatrics 2008;122(Suppl 2):S36-S42.

38. Gagnon AJ. Leduc G, Waghorn K, et al. In-hospital formula supplementation of health breastfeeding newborns. J Hum Lact 2005;21:397-405.

39. Chin LY, Amir LH. Survey of patient satisfaction with the breastfeeding education and support services of The Royal Women's Hospital, Melbourne. BMC Health Serve Res 2008;8:83-87.

40. Lamontagne C, Hamelin AM, St-Pierre M. The breastfeeding experiences of women with major difficulties who use the services of a breastfeeding clinic: A descriptive study. Int Breast J 2008;3:1-45.

Address correspondence to: Andrea Crivelli-Kovach, Ph.D., M.A. Department of Medical Science and Community Health Arcadia University 450 South Easton Road Glenside, PA 19038

E-mail: crivella@arcadia.edu 